the immiscibility field, and behave more like type II alloys do at 10 and 14 carat. Soft and non agehardenable alloys are found in the range of $\mathrm{Ag}^{\prime}$ greater than about 75 per cent. Above 18 carat, the concept of type is not practically useful at all. In this range, the alloys both annealed and heat treated are progressively softer with increasing gold content and approach the properties of 24 carat or pure gold.

If one refers to the colour diagram in Figure 5, and imagines lines drawn from the gold corner through the intersection of the colour boundaries with the 18 carat line and then continued to the $\mathrm{Ag}^{\prime}$ values on the silver-copper axis it can be seen that at 18 carat, red gold alloys occur in the $\mathrm{Ag}^{\prime}$ range 0 to about 40 per cent, yellow alloys in the $\mathrm{Ag}^{\prime}$ range 40 to 80 per cent, and green alloys in the $\mathrm{Ag}^{\prime}$ range from about 80 to 100 per cent. If one now observes where these ranges fall on the 18 carat quasi-binary section in Figure 4, the following generalisations can be made:

All 18 carat green alloys behave like type I soft and non-precipitation hardenable alloys because their compositions fall well outside the immiscibility field. There are no type I red alloys at 18 carat because at low values of $\mathrm{Ag}^{\prime}$ the ordering of the $\mathrm{AuCu}$ phase is available as a hardening mechanism. Yellow alloys at
18 carat fall within the $\mathrm{Ag}^{\prime}$ range of type III alloys at 10 and 14 carat, but behave like 14 carat type II alloys do as indicated above.

The compositions (weight per cent) of three typical 18 carat jewellery alloys are listed below:

$\begin{array}{lccrcc}\text { Colour } & \text { Code } & \mathrm{Au} & \mathrm{Ag} & \mathrm{Cu} & \mathrm{Ag}^{\prime} \% \\ \text { Red } & 200 & 75 & 5 & 20 & 20 \\ \text { Yellow } & 600 & 75 & 15 & 10 & 60 \\ \text { Green } & 900 & 75 & 23 & 2 & 90\end{array}$

The red alloy 200 responds to hardening on heat treating (75 HR45T after solution annealing at $595^{\circ} \mathrm{C}$ followed by hardening at $260^{\circ} \mathrm{C}$ for 2 hours), although its position at 20 per cent $\mathrm{Ag}^{\prime}$ in the 18 carat section of Figure 4 suggests that it might fall outside the influence of both the ordered field and the immiscibility gap. The yellow alloy 600 can be treated to $66 \mathrm{HR} 45 \mathrm{~T}$ by solution annealing at $650^{\circ} \mathrm{C}$ followed by precipitation hardening at $260^{\circ} \mathrm{C}$ for 2 hours. The green alloy 900 is not precipitation hardenable.

\section{References}

1 'Metals Handbook', 8th edition, vol. 8, American Society for Metals, Metals Park, Ohio, 1973

2]. Leuser, Metall, 1949, 3, 105-110, 128

3 C. McCaul, R. Krahn and C. d'Antonio, Trans. Am. Inst. Min. Metall. Eng., 1969, 245, 432-434

The second part of this article will be published in the October 1978 issue of Gold Bulletin.

\title{
The Thermal Conductivity of Gold
}

In low temperature equipment, thermal contact between solid state devices, thermometers etc. and the surroundings may be limited by the conductance of thin gold wires between them. Prediction of the thermal conductivity of such wires at low temperatures is therefore of importance. As a result of measurements reported by V. Novotny from the Department of Physics at the University of Toronto (1), such prediction is now possible.

The conduction of heat in gold is due almost exclusively to electrons, since phonons are effectively scattered. This means that the two conduction processes electrical and thermal, are very similar. In fact there exists a very simple relationship between the two, the Wiedemann-Franz (WF) law, established over a hundred years ago. This is$$
\lambda / \sigma \mathrm{T}=\mathrm{L}_{0}
$$

where $\lambda$ is the thermal conductivity

$\sigma \quad$ is the electrical conductivity

$\mathrm{T}$ is the absolute temperature in degrees $\mathrm{K}$
}

and $L_{0}$ is the Lorenz number, which is a constant of value $2.45 \times 10^{8} \mathrm{~W} \Omega / \mathrm{K}^{2}$. Since the electrical conductivity is much easier to measure, one may derive the thermal conductivity of a metal from the above equation, provided that no deviations from the WF law occur.

The WF law has been established, however, on the basis of elastic scattering. Although this is a good approximation for gold at temperatures below $10 \mathrm{~K}$ and above $300 \mathrm{~K}$, between these temperatures the ratio $\lambda / \sigma \mathrm{T}$ decreases, depending on sample purity. In pure metals, deviation arises from non-elastic electron-phonon scattering processes which generally show up between $\theta_{\mathrm{D}}$ (the Debye temperature, which for gold is about $190 \mathrm{~K})$ and $\theta_{\mathrm{p}} / 30$. In impure metals, deviation arises from the presence of minute amounts $(\sim 10 \mathrm{ppm})$ of magnetic impurties (iron, chromium, manganese).

Since at very low temperatures the electrical conductivity of pure metals is constant ('residual resistivity'), the thermal conductivity should be proportional to temperature. This is actually observed, with $\lambda=\alpha \mathrm{T}$ where $\alpha=\sigma \mathrm{TL}_{0}$. Where deviations due to the failure of the WF law occur, this relationship does not hold, and the thermal conductivity at low temperature can be written as

$$
\lambda=\alpha \mathrm{T}+\beta \mathrm{T}^{2}+\gamma \mathrm{T}^{3}+
$$

where $\beta$ and $\gamma$ are small.

Commercial gold wires are normally made from high purity gold, and Novotny found for the sample (diameter $51 \pm 1 \mu \mathrm{m} ; 99.7$ per cent gold) studied by him that the thermal conductivity was given by

$$
\lambda=0.117 \mathrm{~T}+7 \times 10^{-4} \mathrm{~T}^{2} \quad\left(\mathrm{WK}^{-1} \mathrm{~cm}^{-1}\right)
$$

between 0.8 and $10 \mathrm{~K}$.

The data agree within 20 per cent with those calculated from the measured residual electrical resistivity using the WF law. This implies that predictions of the thermal conductivity of other gold wires at low temperatures can be made to within engineering accuracy over a wide range of residual resistance ratios.

Reference

J.K.

1 V. Novotny, Cryogenics, 1977, 17, 451-452 